Article

\title{
Locating the Principal Sectors for Carbon Emission Reduction on the Global Supply Chains by the Methods of Complex Network and Susceptible-Infective Model
}

\author{
Meihui Jiang
}

check for updates

Citation: Jiang, M. Locating the Principal Sectors for Carbon Emission Reduction on the Global Supply Chains by the Methods of Complex Network and Susceptible-Infective Model. Sustainability 2022, 14, 2821. https://doi.org/10.3390/su14052821

Received: 29 January 2022

Accepted: 27 February 2022

Published: 28 February 2022

Publisher's Note: MDPI stays neutral with regard to jurisdictional claims in published maps and institutional affiliations.

Copyright: (C) 2022 by the author. Licensee MDPI, Basel, Switzerland. This article is an open access article distributed under the terms and conditions of the Creative Commons Attribution (CC BY) license (https:// creativecommons.org/licenses/by/ $4.0 /)$.
School of Management Science and Engineering, Nanjing University of Information Science \& Technology, Nanjing 210044, China; jiangmh@nuist.edu.cn

\begin{abstract}
How to locate the reasonable targets for carbon emission reduction in the complex global supply chain remains a big challenge for policy makers. This paper proposed a novel framework for finding more accurate carbon emission reduction targets, combining multi-regional input-output analysis, complex network approach and an improved susceptible-infective model called the influence spreading model. The results showed that the global embodied carbon emission flow network had the characteristic of being significantly scale-free, and there were a few important industrial sectors in the network with different capabilities, including strength-out, closeness-out, betweenness and clustering coefficient. The simulation results of the influence spreading process showed that the effective infection thresholds were relatively low, which were between 0 and 0.005 due to the significant scale-free characteristic of the global embodied carbon emission flow network. With the change of the infection thresholds, the proportion of the infected sectors significantly decreased from about 0.95 to 0.10 on average, and spread time also decreased from about three rounds to about eight rounds. In the aspects of the spreading scope and spreading speed, the industrial sectors with high closeness-out and betweenness had better performance than the ones with high strength-out. This indicated that the spreading capabilities of industrial sectors which exported significant carbon emissions, such as petroleum, chemicals and non-metallic mineral products in China, were commonly weaker than industrial sectors which occupied the most important positions in the entire supply chain, such as transport equipment in Germany. Hence, the industrial sectors with high global spreading capability and media capability were important for global carbon emission reduction. Such information suggested that the policies for carbon emission reduction should be made based on a global perspective of the supply chain system. This work proved that the policies for carbon emission reduction should be based on a global perspective of supply chain system.
\end{abstract}

Keywords: influence spreading; embodied carbon emissions; multi-regional input-output analysis; complex network; susceptible-infective model

\section{Introduction}

Carbon dioxide emissions are one of the most important greenhouse gas emissions caused by human economic activities [1,2]. Many scholars have studied carbon emissions, aiming to find the essential drivers of carbon emissions and reasonably allocate carbon emission reduction responsibilities [3-5]. Along with the fact that economic globalization is deepening, the world economy has become a complicated and integrated system. There is still a big challenge to locate the vital targets for carbon emission reduction in such a complicated economic system, especially based on the global supply chain perspective.

In the existing literature, when assessing the impacts of human economic activities on the environment, scholars mostly focus on accounting for embodied carbon emissions rather than territorial carbon emissions [6-8]. This is because embodied carbon emissions include all information along the entire supply chain, including production, transportation 
and consumption, which can be helpful for locating the essential drivers of the global carbon emission growth $[9,10]$. Input-output analysis is the major method of accounting for embodied carbon emissions [11,12]. There are also scholars who have applied life cycle assessment (LCA) to study the flow of carbon emissions along the microcosmic production chains [13-15]. These studies have provided a strong foundation for accounting for embodied carbon emissions and finding the essential carbon emission drivers. However, the research above mostly focused on the direct relationships when determining the significant carbon emission contributors. The major measurements for locating the important drivers of the carbon emissions were commonly the total embodied carbon emissions of industrial sectors (sectors) or countries, and the exported carbon emissions or imported carbon emissions embodied in the bilateral trades between sectors or countries [16-19]. The question of how the influence will be spread among all sectors if the production activities of these sectors are changed to reduce carbon emissions still remains unanswered.

In general, the production activities of one sector are not only decided by that sector but also depend on the inputs from other sectors. The flows of the goods and services construct the economic relationships between sectors and provide the possibilities of the spreading of the influence brought by the change of some sectors. Recently, some scholars have proposed that the industrial chain should be regarded as an interactive and complicated system [20,21]. The analysis of the carbon emissions embodied in economic activities should not only focus on two ends of the supply chain but also include the interaction within the intermediate production process between economies [22-24]. In most existing research, this intermediate production process was still treated as a black box. Within intermediate production processes, there are complicated linkages between sectors. The change of the production activities of sectors might influence each other. Due to the existence of the supply chain, this kind of influence might further spread to the downstream sectors [25-27]. This means that when adjusting the production activities of sectors for reducing carbon emissions, the production and carbon emissions of the related sectors are also influenced. Hence, in the complicated supply chain system, it is important to find the key sectors which have strong capabilities to spread influence.

To describe and analyze the structure of the complicated supply chain, many scholars have combined the traditional input-output analysis with the complex network approach and have proposed the concept of the supply chain network [27-30]. Many scholars have studied the complicated characteristics of the supply chain from different perspectives [31-33]. By accounting for the embodied carbon emission flows between sectors, scholars found the different roles of sectors in the supply chain networks based on a systemic perspective [34]. Furthermore, scholars found that some roles of sectors in the supply chain networks would significantly contribute to carbon emissions [35]. However, few studies focused the potential mechanism on how the structure of the supply chain network influences the carbon emissions. In previous studies, the susceptible-infective (SI) model and its derived models have been widely applied to simulate propagation behavior in the complex network, including the propagation of rumor, virus and traffic congestion [36-38]. It has been proven by many scholars that the SI model has the ability to study dynamic mechanisms in the networks. As mentioned above, the economic relationships between sectors make it possible to spread the change of embodied carbon emissions of one sector to others. It is consistent with the concept of the propagation of a virus. Thus, this paper proposes the influence spreading model based on the typical susceptible and infective (SI) model to study the possible cascading influence brought by the change of some individual sectors in the global supply chain system.

The major aim of this paper is to locate the principal sectors for carbon emission reduction in the global supply chain network. Different from existing studies, this paper identifies the key sectors as the policy targets according to their spreading capabilities in global carbon emission flows. This approach can improve the effects of production activity adjustments of sectors and save economic costs for reducing carbon emissions. First, embodied carbon emissions between sectors are accounted for based on EXIOBASE 
data. Then, this paper applies the complex network theory to build the global embodied carbon emission flow network and quantify the different roles of sectors in the network. Finally, the spreading capabilities of sectors with different roles in the global supply chain are simulated in a proposed influence spreading model.

\section{Methods and Materials}

\subsection{Embodied Carbon Emission Accounting}

According to previous research $[39,40]$, the carbon emissions embodied in the output of a production process are defined as the sum of the carbon emissions embodied in the intermediate production process and the direct carbon emissions, shown as:

$$
d_{j}+\sum_{i} e_{i} Z_{i j}=e_{j} x_{j}
$$

$d_{j}$ denotes the direct carbon emissions produced by sector $j . z_{i j}$ represents the intermediate input from sector $i$ to sector $j . x_{j}$ denotes the total output of sector $j . e_{i}$ is the carbon emissions embodied in one unit of inputs from sector $i$, while $e_{j}$ is the carbon emissions embodied in one unit of outputs of sector $j$.

The equation can be rewritten as the matrix form as follows [41]:

$$
\mathbf{d}+\mathbf{e Z}=\hat{\mathbf{e x}}
$$

$\mathbf{d}$ represents the column vector of the direct carbon emissions. $\mathbf{Z}$ is the intermediate matrix. $\mathbf{x}$ denotes the diagonal matrix of the total output. $\mathbf{e}$ is the column vector of the embodied carbon emission coefficient.

Right-multiplying this equation with $\hat{\mathbf{x}}^{-1}$ and replacing $\hat{\mathbf{Z x}}^{-1}$ with $\mathbf{A}$, the embodied carbon emission coefficient could be obtained [41]:

$$
\mathbf{e}=\hat{\mathbf{d x}}^{-1}(\mathbf{I}-\mathbf{A})^{-1}
$$

The embodied carbon emission flows across the production activities are thus obtained as [42]:

$$
\mathbf{E}=\hat{\mathbf{e} Z}
$$

The unit of embodied carbon emissions is kilogram $(\mathrm{kg})$.

\subsection{Global Embodied Carbon Emission Flow Network Construction}

In this paper, the sectors are taken as the nodes, and embodied carbon emissions between sectors are taken as the edges. The weights of edges are the volume of the embodied carbon emissions. The aim of this paper is to study the influence spreading between different sectors, thus, the self-loops within the sectors are not included. Then, a directed and weighted network are obtained, which is called the global embodied carbon emission flow network.

In the traditional studies regarding embodied carbon emissions, scholars usually use the domestic consumption, imports and exports of embodied carbon emissions to quantify the responsibilities of sectors or countries. In this paper, based on a network approach, four network indicators are applied to measure the importance of sectors. The strengthout is chosen to measure the influence degree of one sector on others in the traditional way. Three other special network indicators, including closeness-out, betweenness and clustering coefficient, are also chosen to quantify the spreading capabilities of sectors from the different network structure perspectives, so that comparisons could be made with traditional research. 


\subsubsection{Strength-Out}

In a network, the strength-out of one node denotes the sums of the weights of all edges from this node to others. In this paper, the strength-out of one sector measures how many embodied carbon emissions would flow to others from this sector. Hence, the strength-out is defined as the direct spreading strength of the sectors. It is calculated as follows [35]:

$$
S_{i}=\sum_{j \in N_{i}} w_{i j}
$$

where $N_{i}$ denotes the set of nodes which connect to node $i . w_{i j}$ represents the weights of edges from node $i$ to node $j$.

\subsubsection{Closeness-Out}

In a network, the closeness-out of one node is defined as the inverse of the average shortest path length to all other nodes in the network. In this paper, the closeness-out of a sector measures how many sectors will be passed at least to access every other sector from this sector. Thus, the closeness-out of one sector is defined as its global spreading capability [43]. It is calculated as follows:

$$
C_{i}=\left[\frac{1}{(N-1)} \sum_{j \neq i} p_{i j}\right]^{-1}
$$

where $N$ denotes the number of nodes. $p_{i j}$ represents the shortest path from node $i$ to node $j$.

\subsubsection{Betweenness}

In a network, the betweenness of one node denotes the number of shortest paths which pass through it. In this paper, the betweenness of one sector measures how many shortest paths between two other sectors would pass through these sectors. Thus, the sectors with high betweenness play important roles as bridges between sectors. This is defined as the media capability. The betweenness is obtained as follows [44]:

$$
B_{i}=\frac{\sum_{j}^{n} \sum_{k}^{n} g_{j k}(i) / g_{j k}}{\left(n^{2}-3 n+2\right) / 2}, j \neq k \neq i, j<k
$$

where $g_{j k}(i)$ denotes the number of shortest paths from node $j$ to node $k$ that pass through node $i . g_{j k}$ denotes the number of the shortest paths from node $j$ to node $k$.

\subsubsection{Clustering Coefficient}

In a network, the clustering coefficient of one node denotes the connected degree between its adjacent nodes. In this paper, the clustering coefficient measures the connection degree of one sector's neighbor sectors. If one sector has a high clustering coefficient, it is more possible that its collaboration partners form an industrial cluster around it. Thus, the clustering coefficient is defined as the clustering capability. For a weighted network, the formula for calculating the clustering coefficient is [45]:

$$
C_{i}^{w}=\frac{1}{S_{i}\left(k_{i}-1\right)} \sum_{j, h} \frac{w_{i, j}+w_{i, h}}{2} a_{i, j} a_{i, h} a_{j, h}
$$

where $s_{i}$ is the strength of node $i . a_{i, j}$ represents the element of the adjacency matrix. $k_{i}$ denotes the degree of node $i . w_{i, j}$ is the weight of the edge from node $i$ to node $j$.

\subsection{The Influence Spreading Model}

To simulate the influence spreading performance of different sectors in the global embodied carbon emission flow network, in this paper, an influence spreading model is proposed based on the typical susceptible-infected (SI) model. In an SI model, each individual has two states: susceptible and infected. Let $N$ be the number of individuals. 
At time $t$, the proportion of these two states are $S(t)$ and $I(t)$, respectively, and there is always $S(t)+I(t)=1$. Let $\lambda$ be the infection rate. At each time, the probability that susceptible individuals will be infected by each infected individual will be $\lambda * S(t)$. Because the number of the infected individuals is $N * I(t)$ at time $t$, the number of new infected individuals will be $N * I(t) * \lambda * S(t)$. Thus, the SI model is represented as follows:

$$
\left\{\begin{array}{c}
\frac{d I(t)}{d t}=\lambda * I(t) * S(t) \\
S(t)+I(t)=1
\end{array}\right.
$$

In the typical SI model, there are usually not physical linkages between individuals, for example, virus propagation between persons. Infection depends on the probability to a great extent. Therefore, the infection rate is usually assumed as a constant. However, there are actual economic and technical relationships between sectors in this paper. This represents three differences from the typical SI model. First, only the sectors that have linkages with the infected sectors will be susceptible sectors. Other sectors that do not have linkages with the infected sectors will stay in the third status which is called "untouchable". Second, whether the sectors will be influenced by other sectors depends on some reasonable factors, not only the probability. Thus, the infection rates will be different between sectors. Third, due to the change of the infected sectors, the infection rate of the susceptible sectors also changes over time. Hence, the influence spreading model is proposed as follows:

$$
\left\{\begin{array}{c}
\frac{d I(t)}{d t}=\lambda(t) * I(t) * S(t) \\
S(t)+I(t)+U(t)=1
\end{array}\right.
$$

$\lambda(t)$ is a vector containing all infection rates of susceptible sectors at time $t$.

In the real economy, many factors determine whether one sector will be influenced by another. Here, two major factors are assumed to determine the influence spreading process: the strength of linkages and geographic distance. The flows of goods and services between sectors in the multi-regional input-output table are essentially based on international trade. It is easy to understand that trade would not happen if two countries have a very weak trade relationship and are very far from each other, because the benefit and cost of the trade would not be balanced. Hence, this paper here assumes that if there is a relatively strong connection and close distance between two sectors, they will easily have impact on each other. Hence, for each susceptible sector, the infection rate will be:

$$
\left\{\begin{array}{c}
\lambda_{i}(t)=1-\prod_{j \in N_{i}(t)}\left(1-\lambda_{j i}\right) \\
\lambda_{j i}=\lambda * \text { normalized }\left(\frac{\operatorname{normalized}\left(w_{j i}\right)}{\operatorname{normalized}\left(d_{j i}\right)+1}\right)
\end{array}\right.
$$

For sector $i$, the probability that it would not be influenced by the change in sector $j$ is $1-\lambda_{j i}$. Sector $i$ might be impacted by multiple sectors at time $t$, so the probability that it would not be influenced by all infected sectors is $\prod_{j \in N_{i}(t)}\left(1-\lambda_{j i}\right)$. Thus, the probability that sector $i$ would be infected at time $t$ is $1-\prod_{j \in N_{i}(t)}\left(1-\lambda_{j i}\right)$. $w_{j i}$ is the volume of the embodied carbon emissions flowing from the infected sector $j$ to the susceptible sector $i$. $d_{j i}$ denotes the geographic distance between the countries of sector $j$ and sector $i$. If sector $j$ and sector $i$ belong to the same country, $d_{j i}=0$. This paper assumes that the strength of linkages and geographic distance are two equal factors on influence spreading, thus the normalized procedures are used to eliminate the difference of the dimensions. $\lambda(0 \leq \lambda \leq 1)$ is a constant. When not considering the impacts of linkage strength and distance, the infection rate will be constant, which is consistent with the typical SI model. In general, due to the existence of the linkages between sectors, there are always possibilities for one sector to spread its influence to another. The difference between different sectors of infection could be assumed as the strength of linkages and geographic distance. Hence, here this paper set $\lambda=1$. 


\subsection{Data Source}

In this paper, the multi-regional input-output table in 2015 from the EXIOBASE database was selected for empirical study (https: / / www.exiobase.eu/, version 3.6, accessed on 20 January 2022). It included 200 products produced and consumed in 44 countries (areas) and 5 aggregate regions. In this paper, 200 products were aggregated into 26 products. Because the geographic distance between aggregate regions is difficult to quantify, 44 countries (areas) were selected as the boundary of the world economy system in this paper. The sectors and countries (areas) were listed in Tables A1 and A2 in Appendix A respectively. The carbon emission data were also retrieved from the environment account of the EXIOBASE database. The geographic distance data were from the CEPII (http:/ / www.cepii.fr/, accessed on 18 December 2021).

\section{Results}

\subsection{The Global Embodied Carbon Emission Flow Network}

The original global embodied carbon emission flow network is a $1144 \times 1144$ matrix. It has 1,024,296 edges, and it is nearly a full matrix. As this paper already mentioned in our previous works $[35,46]$, in complex network theory, it is difficult to find the essential structure characteristics in a fully connected network. The common and effective solution for dealing with this problem is to set a threshold to filter the relatively unimportant connections in the network. Thus, this paper retained the edges which occupied $99 \%$ of the total weights in the final networks after ranking the edges by the weights.

In the final global embodied carbon emission flow network, there are 1093 nodes and 34,176 edges, meaning 51 sectors are insular. The network density is 0.029 , indicating the network has a not very well-connected structure. There is a total of $2.687 \times 10^{13} \mathrm{~kg}$ of embodied carbon emissions within the network $\left(3.951 \times 10^{13} \mathrm{~kg}\right.$ total in 2015). According to Figure 1, the degree, degree-in and degree-out of sectors follow power law distribution $p(k) \sim k^{-\alpha}$. This indicated the global embodied carbon emission flow network had the significant scale-free characteristic, and the sectors were connected with preferential attachment. This meant there were a few sectors which played more important roles than other sectors in the structure of the global embodied carbon emission flow network.
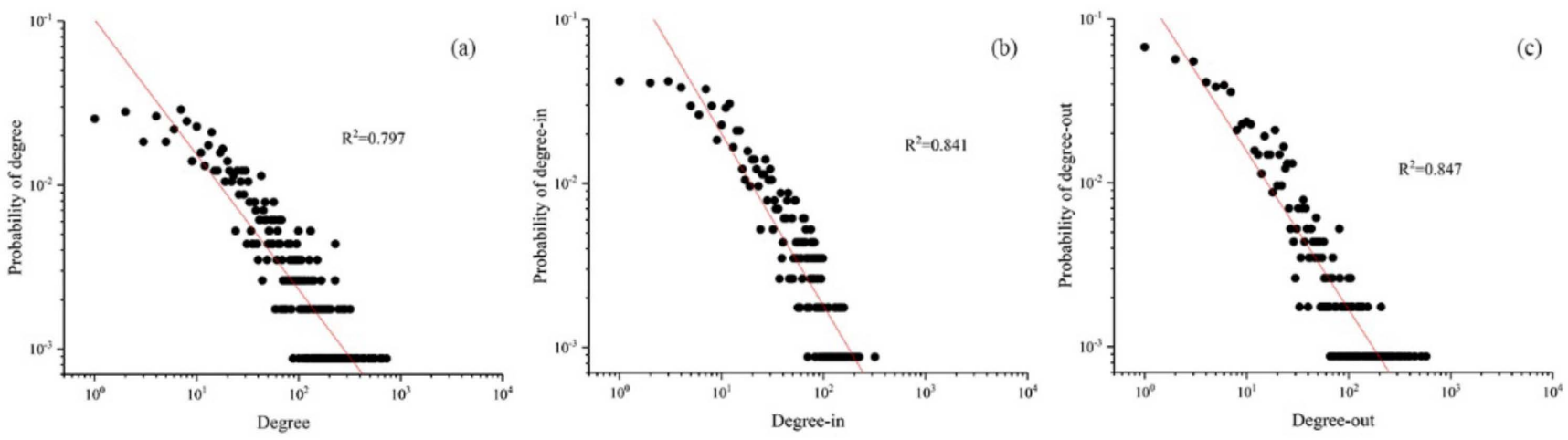

Figure 1. The probability distribution of degree (a), degree-in (b) and degree-out (c). The values on Y-axis are the logarithm of probabilities of different values of degree, degree-in and degree-out. The values on $\mathrm{X}$-axis are the logarithm of values of degree, degree-in and degree-out.

\subsection{The Principal Sectors with Different Spreading Capabilities}

The top 10 sectors with different spreading capabilities were chosen as the principal sectors, shown in Table 1. The results shown there are different important sectors with different roles in the global embodied carbon emission flow network. Many sectors in China had very significant export volumes of embodied carbon emissions, including mining and quarrying (CN11), petroleum, chemicals and non-metallic mineral products (CN15), metal and metal products (CN16), electrical and machinery (CN17), electricity, gas and water (CN20), transport (CN23) and financial intermediation and business activity 
(CN25). Other sectors, including metal and metal products (IN16) and electricity, gas and water (IN20) in India, and electricity, gas and water (US20) in the US, also exported many embodied carbon emissions. In general, if carbon emissions embodied in the production process of these sectors are reduced, it will have significant influence on the importers of intermediate products.

Table 1. The principal sectors with different spreading capabilities.

\begin{tabular}{ccccc}
\hline Rank & Sector & Strength-Out & Sector & Closeness-Out \\
\hline 1 & CN15 & $4.060 \times 10^{12}$ & NL13 & $1.132 \times 10^{-5}$ \\
2 & CN20 & $3.557 \times 10^{12}$ & ES13 & $1.111 \times 10^{-5}$ \\
3 & CN16 & $3.072 \times 10^{12}$ & PT11 & $1.102 \times 10^{-5}$ \\
4 & CN17 & $1.009 \times 10^{12}$ & RU15 & $1.101 \times 10^{-5}$ \\
5 & US20 & $8.942 \times 10^{11}$ & CN15 & $1.100 \times 10^{-5}$ \\
6 & IN20 & $5.852 \times 10^{11}$ & CN17 & $1.099 \times 10^{-5}$ \\
7 & CN11 & $5.843 \times 10^{11}$ & MX13 & $1.099 \times 10^{-5}$ \\
8 & CN23 & $5.574 \times 10^{11}$ & DE15 & $1.098 \times 10^{-5}$ \\
9 & CN25 & $3.323 \times 10^{11}$ & US15 & $1.098 \times 10^{-5}$ \\
10 & IN16 & $3.227 \times 10^{11}$ & RU23 & $1.097 \times 10^{-5}$ \\
\hline Rank & Sector & Clustering & Sector & Betweenness \\
\hline 1 & Coefficient & & 0.079 \\
2 & BG24 & 1.000 & CN15 & 0.071 \\
3 & HR06 & 1.000 & RU15 & 0.063 \\
4 & LT05 & 1.000 & CN17 & 0.040 \\
5 & RO13 & 1.000 & US15 & 0.031 \\
6 & CH08 & 1.000 & DE15 & 0.029 \\
7 & KR13 & 0.954 & DE17 & 0.023 \\
8 & SE12 & 0.944 & CN16 & 0.020 \\
9 & FI12 & 0.943 & IE25 & 0.019 \\
10 & US13 & 0.910 & IN15 & 0.017 \\
\hline
\end{tabular}

Similar to the strength-out, some typical heavy industrial sectors also had high closeness-out, including petroleum, chemicals and non-metallic mineral products, and electrical and machinery in China. Although other sectors, such as forestry, etc., in the Netherlands (NL13) and Spain (13), mining and quarrying in Portugal (PT11), petroleum, chemicals and non-metallic mineral products in Russia (RU15), Germany (DE15) and the US (US15), and transport in Russia (RU13) did not export as much embodied carbon emissions as China, the changes in these locations can quickly influence many sectors in the global supply chain. This is because most sectors are located in Europe. The countries in Europe usually have the closer connections with each other than other countries.

The sectors with high clustering coefficients include fish in Lithuania (LT05), dairy and eggs in Croatia (HR06), meat n.e.c. in China (CH08), textiles, leather and wearing apparel in Sweden (SE12) and Finland (FI12), forestry, etc., in Romania (RO13), South Korea (KR13) and Mexico (MX13), and post and telecommunications in Bulgaria (BG24). It can be seen that most sectors were food and light industrial sectors. The products of these sectors were usually produced and consumed in the domestic markets. Hence, these sectors and their partners usually form relatively tight clusters in the global economy system.

There are also some sectors which had high betweenness, including petroleum, chemicals and non-metallic mineral products in China (CH15), Russia (RU15), the US (US15), Germany (DE15) and India (IN15), metal and metal products in China (CH16), electrical and machinery in China (CH17) and Germany (GE17), and transport equipment in Germany (DE18). These sectors usually purchase the raw materials or intermediate products for production, then sell the products to other sectors. Additionally, China, Russia, the US, India and Germany all play very important roles in the international trade. Thus, these sectors had significant bridge effects in the global supply chain. 


\subsection{The Simulation of the Influence Spreading Process}

3.3.1. The Sensitivity Analysis of the Infection Thresholds

To compare the difference between different spreading capabilities of sectors, the top 10 sectors were chosen as infection sources. Then, the influence spreading model was applied to simulate the influence spreading process in the global embodied carbon emission flow network. As this paper mentioned before, there are always possibilities of infection if one sector connects to another by setting $\lambda=1$. To compare the differences of the spreading capabilities of the selected sectors under different scenarios, this paper set 1001 infection thresholds from 0 to 1 . If the infection rate of one susceptible sector is larger or equal to the infection threshold, it will be infected.

According to Figure 2, the total infection proportion had a significant decrease when the infection threshold increased from 0 to 0.005 , then was kept stable when the infection threshold was between 0.005 and 1 . This indicated that the influence spreading process of embodied carbon emissions in the network was sensitive when the infection threshold was between 0 and 0.005 . When the infection threshold was in this range, the influence spreading process would have significant differences in different scenarios. Therefore, six scenarios were chosen to analyze the influence spreading process of embodied carbon emissions with infection thresholds of $0,0.001,0.002,0.003,0.004$ and 0.005 . The reason for the small values of the infection thresholds is because the global embodied carbon emission flow network had significant scale-free characteristics. The majority of carbon emissions were embodied in only a few goods and service flows between sectors. Thus, the proportions of the embodied carbon emissions between most sectors were relatively low. Due to the purpose of the infection threshold, its specific value would not influence the results.

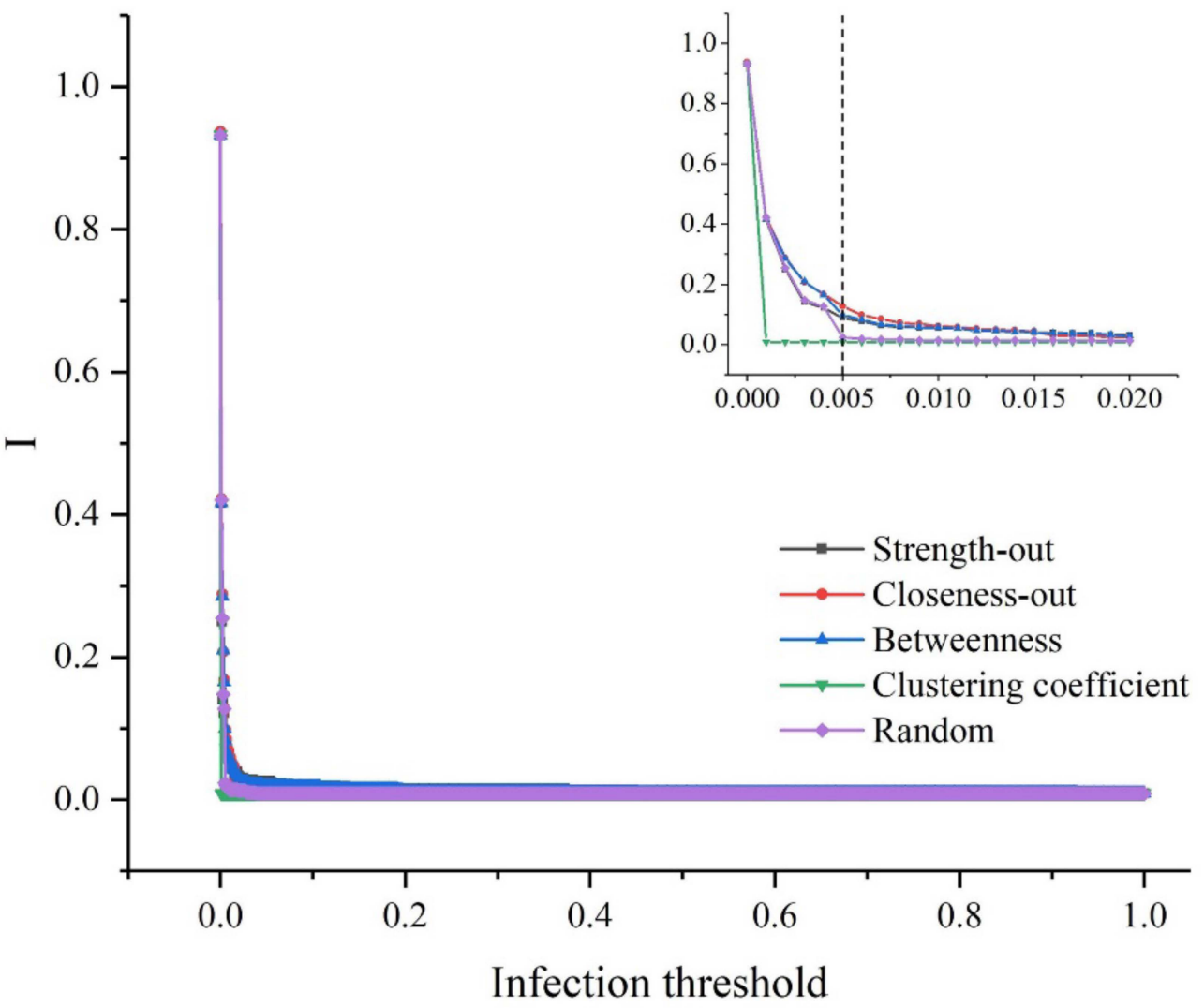

Figure 2. The total infection proportion with different infection thresholds. The values on Y-axis are the proportion of the total infected sectors. The values on $\mathrm{X}$-axis are the different infection thresholds.

According to Figure 3, the selection of infection thresholds had significant influence on the influence spreading process of carbon emissions between sectors. The proportion of the infected sectors significantly decreased by about 0.95 to 0.10 on average with the 
increase of the infection threshold. In addition, the spread speed also decreased with the change of the infection threshold. When the infection threshold was 0 , the spread process could be completed after three rounds of infection. When the infection threshold was 0.005 , it required about eight rounds of infection.
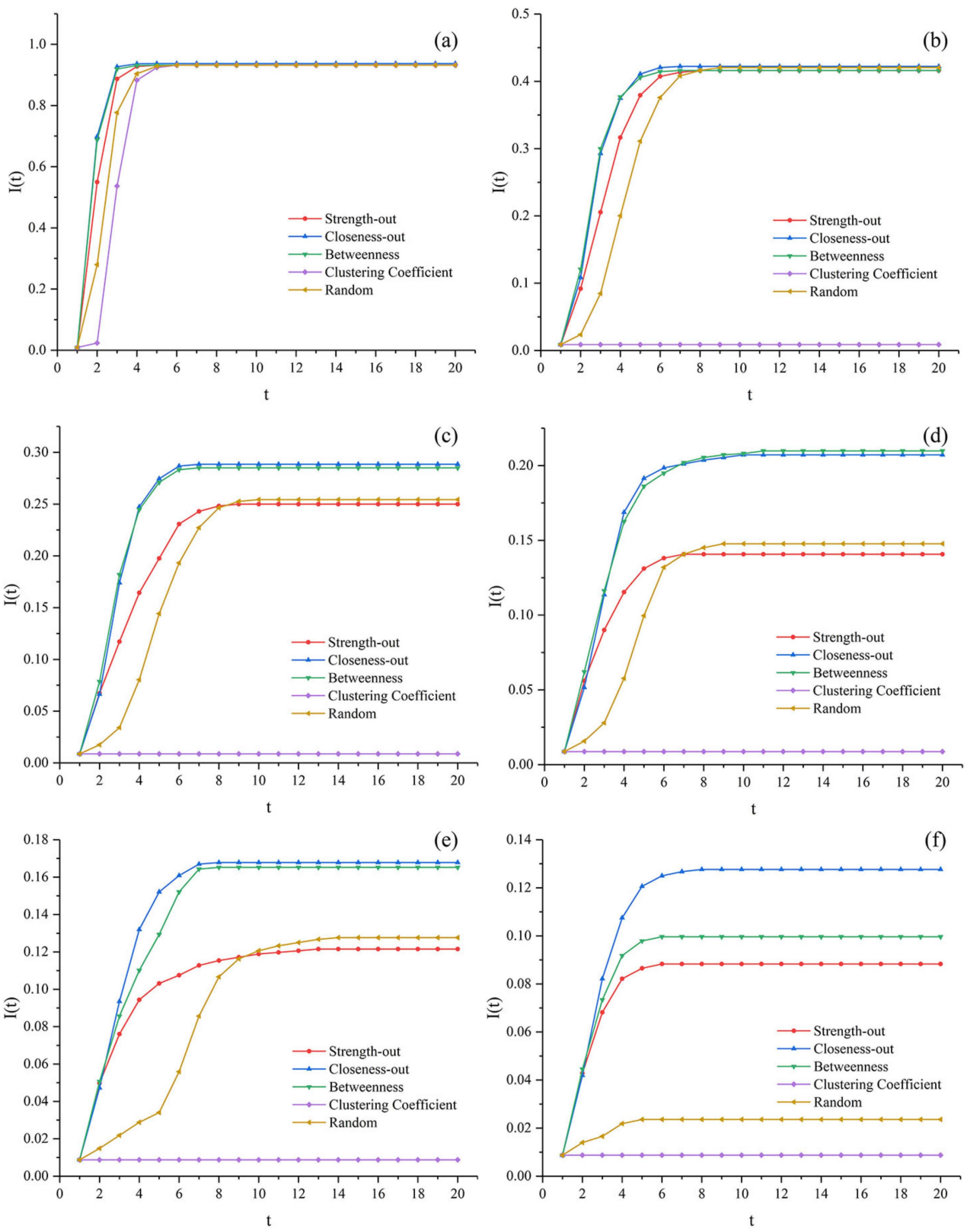

Figure 3. The influence spreading process with different infection thresholds. (a) Infection threshold $=0$; (b) infection threshold $=0.001 ;$ (c) infection threshold $=0.002 ;$ (d) infection threshold $=0.003$; (e) infection threshold $=0.004$; (f) infection threshold $=0.005$. The values on Y-axis are the proportion of the infected sectors at time $t$. The values on $X$-axis are different times.

\subsubsection{The Performance of Sectors with Different Spread Capabilities}

Compared to the randomly selected sectors, the sectors with high strength-out, closenessout and betweenness generally had better performance in the selected six scenarios. Especially in the high infection threshold scenarios, the influence spreading process might not happen if randomly selecting some sectors as the policy targets (Figure $3 \mathrm{~d}-\mathrm{f}$ ). This indicated that it is reasonable and necessary to select some important sectors as the policy targets. The special positions of these sectors in the supply chain would be helpful for 
the influence spreading of the related policies. Among the selected four capabilities of sectors in the global embodied carbon emission flow network, Figure 3a-f shows that the sectors with high betweenness and closeness-out had good spreading performance. With the increase of the infection threshold, the advantage of these sectors became more and more significant. However, the sectors with high strength-out did not perform as well as the sectors with high betweenness and closeness-out. Although these sectors had important direct relationships with neighbor sectors, the influence might be limited based on the full industrial chain perspective. Otherwise, the spreading process did not happen if the sources had a high clustering effect in the network, according to Figure 3. This might be because the influence is limited within the clusters rather than spreading to the outside of clusters.

\section{Discussion and Conclusions}

To locate the policy targets for carbon emission reduction, this paper applied the influence spreading model to compare the spreading capabilities of different sectors with different roles in the global embodied carbon emission flow network. First, the embodied carbon emission flows between sectors were accounted for using multi-regional inputoutput analysis based on the EXIOBASE data. Then, this paper built the global embodied carbon emission flow network and quantified four-dimensional roles of sectors, including strength-out, closeness-out, betweenness and clustering coefficient, using a complex network approach. Finally, the influence spreading model was proposed by improving the typical susceptible-infected (SI) model to simulate the influence spreading process of different sectors. The main results are as follows.

First, the network analysis showed that the global embodied carbon emission flow network had a significant scale-free characteristic. It indicated that the connections between sectors were not even and random. There were a few important sectors in the network. The results also showed that the roles of different sectors in the network were different. For example, electricity, gas and water in China had the greatest export volume of embodied carbon emissions, but it had a very limited global influence in the network. This means this sector might have a significant influence on its neighbor sectors.

Second, the results of the sensitivity analysis showed that the effective infection thresholds were relatively low, which were between 0 and 0.005 . This might be caused by the significant scale-free characteristic of the global embodied carbon emission flow network. The majority of carbon emissions were embodied in only a few goods and service flows between sectors. With the increase of the infection threshold, the proportion of the infected sectors significantly decreased from about 0.95 to 0.10 , and the spread speed decreased from about three rounds to eight rounds of infection.

Third, the simulation of the influence spreading process showed that the sectors with special roles in the network surely had better performance when compared with randomly selected sectors. This meant that the structure of the global supply chain could be used for the spreading of policy influence. Although previous studies have proven that some sectors with high energy consumption are responsible for climate change, our results indicated that sectors with important indirect relationships in the supply chain have a significant role in the influence spreading of related policies, including the global spreading capability (closeness-out) and the media capability (betweenness). Change in the sectors with high closeness-out and betweenness might have a better spreading speed and scope, which could be helpful for obtaining the maximized effects with minimal cost.

In summary, although some sectors, such as petroleum, chemicals and non-metallic mineral products in China, electricity, gas and water in India, and electricity, gas and water in the US exported significant embodied carbon emissions, the influences on the total carbon emissions of the entire global supply chain might be relatively limited. If the production activities of these sectors change, only the neighbor sectors would be influenced. Although the sectors including petroleum, chemicals and non-metallic mineral products in Germany, electrical and machinery in China, and transport equipment in Germany did 
not export significant embodied carbon emissions, changes in production activities would widely influence most sectors in the global supply chain. Hence, from a global perspective, the contribution of the sectors with high global spreading capability and media capability to carbon emissions should be recognized and given attention.

Funding: This research is supported by funds from the Startup Foundation for Introducing Talent of NUIST and the Philosophy and Social Sciences Research Project in Jiangsu Universities (2021SJA0165).

Institutional Review Board Statement: Not applicable.

Informed Consent Statement: Not applicable.

Data Availability Statement: Not applicable.

Conflicts of Interest: The authors declare no conflict of interest.

\section{Appendix A}

Table A1. Classification of sectors.

\begin{tabular}{cl}
\hline Sector Code & \\
\hline 1 & Crops, vegetables, fruit and nuts \\
2 & Cattle \\
3 & Animal husbandry n.e.c. \\
4 & Raw milk \\
5 & Fish \\
6 & Dairy and eggs \\
7 & Beef \\
8 & Meat n.e.c. \\
9 & Drinks and tobacco \\
10 & Food n.e.c. \\
11 & Mining and quarrying \\
12 & Textiles, leather and wearing apparel \\
13 & Forestry, etc. \\
14 & Wood, paper and publishing \\
15 & Petroleum, chemicals and non-metallic mineral products \\
16 & Metal and metal products \\
17 & Electrical and machinery \\
18 & Transport equipment \\
19 & Manufacturing and recycling \\
20 & Electricity, gas and water \\
21 & Construction \\
22 & Sale, maintenance and repair of vehicles; fuel; trade; hotels and restaurants \\
23 & Transport \\
24 & Post and telecommunications \\
25 & Financial intermediation and business activity \\
26 & Public administration; education; health; recreation; other services \\
\hline
\end{tabular}

Table A2. Countries (areas) and their codes.

\begin{tabular}{cccc}
\hline Code & Country & Code & Country \\
\hline AT & Austria & PT & Portugal \\
BE & Belgium & RO & Romania \\
BG & Bulgaria & SE & Sweden \\
CY & Cyprus & SI & Slovenia \\
CZ & Czech Republic & SK & Slovakia \\
DE & Germany & GB & United Kingdom \\
DK & Denmark & US & United States \\
EE & Estonia & JP & Japan \\
ES & Spain & CN & China \\
FI & Finland & CA & Canada \\
FR & France & KR & South Korea \\
GR & Greece & BR & Brazil \\
HR & Croatia & IN & India \\
HU & Hungary & MX & Mexico \\
IE & Ireland & RU & Russia \\
IT & Italy & AU & Australia \\
LT & CH & Switzerland \\
LU & Luxembouria & TR & Turkey \\
LV & Latvia & TW & Taiwan \\
MT & Malta & NO & Norway \\
PL & Netherlands & ID & Indonesia \\
\end{tabular}




\section{References}

1. Tokarska, K.B.; Gillett, N.P. Cumulative carbon emissions budgets consistent with 1.5 degrees C global warming. Nat. Clim. Chang. 2018, 8, 296-299. [CrossRef]

2. Zheng, B.; Wang, S.; Xu, J.X. A Review on the $\mathrm{CO}_{2}$ Emission Reduction Scheme and Countermeasures in China's Energy and Power Industry under the Background of Carbon Peak. Sustainability 2022, 14, 879. [CrossRef]

3. Rong, Y.Y.; Jia, J.S.; Ju, M.; Chen, C.D.; Zhou, Y.M.; Zhong, Y.X. Multi-Perspective Analysis of Household Carbon Dioxide Emissions from Direct Energy Consumption by the Methods of Logarithmic Mean Divisia Index and sigma Convergence in Central China. Sustainability 2021, 13, 9285. [CrossRef]

4. Zhang, H.W.; Zhang, L.Q.; Wang, K.Y.; Shi, X.P. Unveiling Key Drivers of Indirect Carbon Emissions of Chinese Older Households. Sustainability 2019, 11, 5740. [CrossRef]

5. Xu, H.R.; Ren, Y.A.; Zhang, W.X.; Meng, W.J.; Yun, X.; Yu, X.Y.; Li, J.; Zhang, Y.Z.; Shen, G.F.; Ma, J.M.; et al. Updated Global Black Carbon Emissions from 1960 to 2017: Improvements, Trends, and Drivers. Environ. Sci. Technol. 2021, 55, 7869-7879. [CrossRef] [PubMed]

6. Zhong, Z.Q.; Jiang, L.; Zhou, P. Transnational transfer of carbon emissions embodied in trade: Characteristics and determinants from a spatial perspective. Energy 2018, 147, 858-875. [CrossRef]

7. Long, R.Y.; Li, J.Q.; Chen, H.; Zhang, L.L.; Li, Q.W. Embodied carbon dioxide flow in international trade: A comparative analysis based on China and Japan. J. Environ. Manag. 2018, 209, 371-381. [CrossRef]

8. Li, Y.E.; Li, J.D. How Does China's Economic Policy Uncertainty Affect the Sustainability of Its Net Grain Imports? Sustainability 2021, 13, 6899. [CrossRef]

9. Liu, H.G.; Fan, X.M. Value-Added-Based Accounting of $\mathrm{CO}_{2}$ Emissions: A Multi-Regional Input-Output Approach. Sustainability 2017, 9, 2220. [CrossRef]

10. Deng, G.Y.; Xu, Y. Accounting and structure decomposition analysis of embodied carbon trade: A global perspective. Energy 2017, 137, 140-151. [CrossRef]

11. Zhang, Z.K.; Zhu, K.F.; Hewings, G.J.D. A multi-regional input-output analysis of the pollution haven hypothesis from the perspective of global production fragmentation. Energy Econ. 2017, 64, 13-23. [CrossRef]

12. Xu, P.Q.; Shao, L.; Geng, Z.H.; Guo, M.L.; Wei, Z.J.; Wu, Z. Consumption-Based Carbon Emissions of Tianjin Based on Multi-Scale Input-Output Analysis. Sustainability 2019, 11, 6270. [CrossRef]

13. Chastas, P.; Theodosiou, T.; Kontoleon, K.J.; Bikas, D. Normalising and assessing carbon emissions in the building sector: A review on the embodied $\mathrm{CO}_{2}$ emissions of residential buildings. Build Environ. 2018, 130, 212-226. [CrossRef]

14. Zhang, X.C.; Zheng, R.Y.; Wang, F.L. Uncertainty in the life cycle assessment of building emissions: A comparative case study of stochastic approaches. Build Environ. 2019, 147, 121-131. [CrossRef]

15. Robati, M.; Daly, D.; Kokogiannakis, G. A method of uncertainty analysis for whole-life embodied carbon emissions $\left(\mathrm{CO}_{2}\right.$-e) of building materials of a net-zero energy building in Australia. J. Clean. Prod. 2019, 225, 541-553. [CrossRef]

16. Ding, T.; Ning, Y.D.; Zhang, Y. The contribution of China's bilateral trade to global carbon emissions in the context of globalization. Struct. Chang. Econ. Dyn. 2018, 46, 78-88. [CrossRef]

17. Zhang, W.; Li, J.; Li, G.X.; Guo, S.C. Emission reduction effect and carbon market efficiency of carbon emissions trading policy in China. Energy 2020, 196, 9. [CrossRef]

18. Liu, Z.; Meng, J.; Deng, Z.; Lu, P.; Guan, D.B.; Zhang, Q.; He, K.B.; Gong, P. Embodied carbon emissions in China-US trade. Sci. China-Earth Sci. 2020, 63, 1577-1586. [CrossRef]

19. Hotak, S.; Islam, M.; Kakinaka, M.; Kotani, K. Carbon emissions and carbon trade balances: International evidence from panel ARDL analysis. Environ. Sci. Pollut. Res. 2020, 27, 24115-24128. [CrossRef]

20. Liao, H.; Shen, J.; Wu, X.T.; Chen, B.K.; Zhou, M.Y. Empirical topological investigation of practical supply chains based on complex networks. Chin. Phys. B 2017, 26, 7. [CrossRef]

21. He, G.; Zhou, L.; Dai, Y.Y.; Dang, Y.G.; Ji, X. Coal Industrial Supply Chain Network and Associated Evaluation Models. Sustainability 2020, 12, 9919. [CrossRef]

22. Xia, Q.; Tian, G.L.; Wu, Z. Examining embodied carbon emission flow relationships among different industrial sectors in China Sustain. Prod. Consum. 2022, 29, 100-114. [CrossRef]

23. Wang, X.P.; Yu, J.Q.; Song, J.Z.; Di, X.L.; Wang, R.R. Structural evolution of China's intersectoral embodied carbon emission flow network. Environ. Sci. Pollut. Res. 2021, 28, 21145-21158. [CrossRef] [PubMed]

24. Wang, X.C.; Tang, X.; Feng, Z.H.; Zhang, Y. Characterizing the Embodied Carbon Emissions Flows and Ecological Relationships among Four Chinese Megacities and Other Provinces. Sustainability 2019, 11, 2591. [CrossRef]

25. Wu, B.; Huang, W.Y.; Liu, P.F. Carbon Reduction Strategies Based on an NW Small-World Network with a Progressive Carbon Tax. Sustainability 2017, 9, 1747. [CrossRef]

26. Wang, L.; Zheng, J.J. Research on low-carbon diffusion considering the game among enterprises in the complex network context. J. Clean. Prod. 2019, 210, 1-11. [CrossRef]

27. Chen, B.; Wang, X.B.; Li, Y.L.; Yang, Q.; Li, J.S. Energy-induced mercury emissions in global supply chain networks: Structural characteristics and policy implications. Sci. Total Environ. 2019, 670, 87-97. [CrossRef]

28. Hanaka, T.; Kagawa, S.; Ono, H.; Kanemoto, K. Finding environmentally critical transmission sectors, transactions, and paths in global supply chain networks. Energy Econ. 2017, 68, 44-52. [CrossRef] 
29. Tokito, S. Environmentally-Targeted Sectors and Linkages in the Global Supply-Chain Complexity of Transport Equipment. Ecol. Econ 2018, 150, 177-183. [CrossRef]

30. Fu, Y.; Xue, L.; Yan, Y.X.; Pan, Y.; Wu, X.F.; Shao, Y. Energy Network Embodied in Trade along the Belt and Road: Spatiotemporal Evolution and Influencing Factors. Sustainability 2021, 13, 530. [CrossRef]

31. Duan, Y.W.; Jiang, X.M. Visualizing the change of embodied $\mathrm{CO}_{2}$ emissions along global production chains. J. Clean. Prod. 2018, 194, 499-514. [CrossRef]

32. Gao, C.X.; Su, B.; Sun, M.; Zhang, X.L.; Zhang, Z.H. Interprovincial transfer of embodied primary energy in China: A complex network approach. Appl. Energy 2018, 215, 792-807. [CrossRef]

33. Hong, S.Y.; Wang, H.R.; Cheng, T. Circulation Characteristic Analysis of Implied Water Flow Based on a Complex Network: A Case Study for Beijing, China. Water 2018, 10, 834. [CrossRef]

34. Wang, Y.Y.; Lei, Y.L.; Fan, F.Y.; Li, L.; Liu, L.N.; Wang, H.T. Inter-provincial sectoral embodied $\mathrm{CO}_{2}$ net-transfer analysis in China based on hypothetical extraction method and complex network analysis. Sci. Total Environ. 2021, 786, 13. [CrossRef] [PubMed]

35. Jiang, M.; Gao, X.Y.; Guan, Q.; Hao, X.Q.; An, F. The structural roles of sectors and their contributions to global carbon emissions: A complex network perspective. J. Clean. Prod. 2019, 208, 426-435. [CrossRef]

36. Pu, C.L.; Li, S.Y.; Yang, X.X.; Xu, Z.Q.; Ji, Z.X.; Yang, J. Traffic-driven SIR epidemic spreading in networks. Phys. A-Stat. Mech. Its Appl. 2016, 446, 129-137. [CrossRef]

37. Dadlani, A.; Kumar, M.S.; Murugan, S.; Kim, K. System Dynamics of a Refined Epidemic Model for Infection Propagation Over Complex Networks. IEEE Syst. J. 2016, 10, 1316-1325. [CrossRef]

38. Liu, Q.M.; Li, T.; Sun, M.C. The analysis of an SEIR rumor propagation model on heterogeneous network. Phys. A-Stat. Mech. Its Appl. 2017, 469, 372-380. [CrossRef]

39. Wang, X.C.; Klemes, J.J.; Wang, Y.T.; Dong, X.B.; Wei, H.J.; Xu, Z.H.; Varbanov, P.S. Water-Energy-Carbon Emissions nexus analysis of China: An environmental input-output model-based approach. Appl. Energy 2020, 261, 12. [CrossRef]

40. Wu, X.D.; Guo, J.L.; Li, C.H.; Chen, G.Q.; Ji, X. Carbon emissions embodied in the global supply chain: Intermediate and final trade imbalances. Sci. Total Environ. 2020, 707, 23. [CrossRef]

41. Hertwich, E.G.; Wood, R. The growing importance of scope 3 greenhouse gas emissions from industry. Environ. Res. Lett. 2018, 13, 11. [CrossRef]

42. Sun, X.Q.; An, H.Z.; Gao, X.Y.; Jia, X.L.; Liu, X.J. Indirect energy flow between industrial sectors in China: A complex network approach. Energy 2016, 94, 195-205. [CrossRef]

43. Stella, M.; De Domenico, M. Distance Entropy Cartography Characterises Centrality in Complex Networks. Entropy 2018, 20, 268. [CrossRef] [PubMed]

44. Mahyar, I.; Hasheminezhad, R.; Ghalebi, K.E.; Nazemian, A.; Grosu, R.; Movaghar, A.; Rabiee, H.R. Compressive sensing of high betweenness centrality nodes in networks. Phys. A-Stat. Mech. Its Appl. 2018, 497, 166-184. [CrossRef]

45. Yin, H.; Benson, A.R.; Leskovec, J. Higher-order clustering in networks. Phys. Rev. E. 2018, 97, 11. [CrossRef] [PubMed]

46. Jiang, M.; An, H.Z.; Gao, X.Y.; Liu, S.Y.; Xi, X. Factors driving global carbon emissions: A complex network perspective. Resour. Conserv. Recyl. 2019, 146, 431-440. [CrossRef] 